To Maega $\mid$ Jurnal Pengabdian Masyarakat

Bulan-Tahun, Vol..., No..., hal...

$\operatorname{ISSN}(P): 2622-6332 ; \operatorname{ISSN}(E): 2622-6340$

http://www.ojs.unanda.ac.id/index.php/tomaega

\title{
Membangun Masyarakat Peduli Lingkungan Pesisir Melalui Edukasi Kepada Masyarakat Kota Tanjungpinang Terkait Pelestarian Daerah Pesisir
}

\author{
Elfa Oprasmani 1,a, *, Trisna Amelia 2, b, Erda Muhartati 3, c \\ 1, 2, 3 Pendidikan Biologi, FKIP, Universitas Maritim Raja Ali Haji \\ a,b,cEmail: elfaoprasmani@umrah.ac.id; trisna.amelia@umrah.ac.id; \\ erdamuhartati@umrah.ac.id \\ *Correspondent Email: elfaoprasmani@umrah.ac.id
}

Article History:

Received: 12-06-2020; Received in Revised: 23-06-2020; Accepted: 06-07-2020

DOI: http://dx.doi.org/10.35914/tomaega.v3i2.372

\begin{abstract}
Abstrak
Kota Tanjungpinang merupakan ibukota Provinsi Kepulauan Riau yang juga termasuk daerah pesisir. Sebagai Kota yang sedang berkembang, maka kepadatan penduduk di Kota Tanjungpinang terus meningkat secara signifikan. Dampak akibat padatnya jumlah penduduk yaitu alih fungsi lahan sebagai lahan permukiman, industri, sarana dan prasarana serta kegiatan lainnya. Salah satu alih fungsi lahan yang terjadi yaitu alih fungsi kawasan mangrove yang menyebabkan rusaknya ekosistem di daerah pesisir dan lautnya. Kurangnya pengetahuan dan kesadaran akan dampak rusaknya ekosistem mangrove di daerah pesisir serta kurangnya pemahaman terhadap upaya pelestarian ekosistem mangrove menyebabkan permasalahan tersebut terus terjadi. Pengabdian masyarakat yang diadakan oleh tim Pengabdian Universitas Maritim Raja Ali Haji (UMRAH) ditujukan kepada masyarakat Kota Tanjungpinang dengan metode pendidikan/edukasi kepada masyarakat Tanjungpinang untuk memberikan pengetahuan tentang peran penting ekosistem mangrove bagi daerah pesisir, meningkatkan kesadaran dan kepedulian masyarakat dalam melestarikan daerah pesisir serta mendorong masyarakat untuk ikut melakukan konservasi mangrove. Kegiatan pengabdian berjalan dengan baik. Hal ini terlihat dari keinginan masyarakat untuk ikut menandatangani janji pelestarian lingkungan.
\end{abstract}

Kata Kunci: edukasi masyarakat, pelestarian, daerah pesisir

\begin{abstract}
Tanjungpinang City is the capital of Riau Islands Province which is also a coastal area. As a developing city, the population density in Tanjungpinang City continues to increase significantly. The impact due to dense population is the conversion of land as residential land, industry, facilities and infrastructure as well as other activities. One of the functions of land conversion is the conversion of mangrove areas which causes damage to the ecosystem in the coastal and marine areas. Lack of knowledge and awareness of the impact of damage to mangrove ecosystems in coastal areas and a lack of understanding of efforts to conserve mangrove ecosystems causes these problems to continue to occur. Community service provided by the Raja Ali Haji Maritime University (UMRAH) community service team is aimed at the people of the city of Tanjungpinang with education methods to the Tanjungpinang community to provide knowledge about the
\end{abstract}


[67 ] Elfa Oprasmani, dkk / To Maega : Jurnal Pengabdian Masyarakat, Vol.3; No.2; Agustus, 2020

important role of mangrove ecosystems in coastal areas, increase public awareness and concern in preserving coastal areas and encourage the community to participate in mangrove conservation. Community service activities went well. This can be seen from the desire of the community to join in signing environmental pledges.

Key Word: community education, preservation, coastal area

\section{Pendahuluan}

Indonesia termasuk daerah maritim karena memiliki luas lautan yang mencapai $70 \%$ dari total wilayahnya (Indriawati dan Retnowaty, 2018). Sebagai negara maritim, banyak masyarakat yang memanfaatkan potensi laut untuk kehidupan, sehingga banyak masyarakat yang hidup dan bermukim di daerah pesisir. Provinsi Kepulauan Riau merupakan wilayah maritim dengan garis pantai sepanjang $2.367,6 \mathrm{~km}$ dengan luas wilayah $251.810 \mathrm{~km}^{2}$, dimana $4 \%$ wilayahnya merupakan daratan dan 96\% merupakan lautan (Barenlitbang Provinsi Kepulauan Riau, 2019).

Sebagai kota termasuk daerah pesisir dan sedang berkembang, maka kepadatan penduduk di Kota Tanjungpinang terus meningkat secara signifikan. Padatnya jumlah penduduk berpengaruh terhadap kerusakan lingkungan yang disebabkan oleh ulah manusia seperti buang sampah sembarangan, sanitasi dan drainase yang buruk (Pratiwi, 2017). Dampak lain akibat padatnya jumlah penduduk yaitu alih fungsi lahan sebagai lahan permukiman, industri, sarana dan prasarana serta kegiatan lainnya. Salah satu alih fungsi lahan yang tidak dapat terelakkan adalah alih fungsi kawasan mangrove, sehingga hal ini dapat berdampak rusaknya ekosistem di daerah pesisir dan lautnya. Keberadaan hutan mangrove di Kota Tanjungpinang mulai terancam akibat beralih fungsi (Kurniati dan Nazaki, 2017).

Luas total ekosistem mangrove yang terdapat di kawasan pesisir Kota Tanjungpinang adalah seluas 774,25 hektar, beberapa kawasan mangrove di Kota Tanjungpinang telah mengalami kerusakan yang memprihatinkan, salah satunya kawasan mangrove di Pulau Dompak akibat pembangunan sarana dan prasarana seperti jembatan dan kawasan perkantoran (Lestari, 2015). Berdasarkan hasil observasi di lapangan, beberapa kawasan mangrove di Senggarang juga mengalami kerusakan akibat aktivitas penambangan bauksit serta pembukaan lahan untuk kawasan permukiman. Selain itu, pencemaran akibat aktivitas manusia seperti limbah detergen dan limbah plastik juga dapat menyebabkan matinya tumbuhan mangrove.

Kurangnya pengetahuan dan kesadaran akan dampak rusaknya ekosistem mangrove di daerah pesisir serta kurangnya pemahaman terhadap upaya pelestarian ekosistem mangrove ini, menyebabkan permasalahan tersebut terus berlangsung. Sehingga apabila tidak segera diatasi maka kerusakan ekosistem ini akhirnya dapat menyebabkan dampak negatif bagi kehidupan manusia. Rusaknya license (https://creativecommons.org/licenses/by-sa/4.0/). 
ekosistem mangrove dapat menyebabkan terganggunya keseimbangan ekosistem. Selain itu rusaknya ekosistem mangrove dapat menyebabkan abrasi di daerah pantai, sehingga daerah daratan menjadi semakin berkurang (Tjandra dan Siagian, 2011).

Salah satu solusi untuk mengatasi kerusakan ekosistem mangrove adalah dengan konservasi dan rehabilitasi mangrove. Konservasi mangrove adalah upaya pelestarian mangrove dengan melibatkan masyarakat sekitar (Indriawati dan Retnowaty, 2018). Masyarakat pesisir memegang peranan penting dalam konservasi, untuk itu perlu penyuluhan atau sosialisasi kepada masyarakat pesisir khususnya Kota Tanjungpinang agar lebih peduli terhadap daerah pesisir. Penyuluhan atau sosialisasi dengan menyampaikan informasi kepada masyarakat dapat membuka pola pikir dan meningkatkan wawasan masyarakat (Rahmawati, $\mathrm{dkk}, 2020)$. Dengan terbukanya pola pikir dan meningkatnya wawasan masyarakat tentang fungsi dan manfaat ekosistem mangrove diharapkan dapat meningkatkan kesadaran masyarakat dalam menjaga lingkungan khususnya daerah pesisir.

Berdasarkan permasalahan tersebut maka perlu dilakukan kegiatan pengabdian kepada masyarakat yaitu edukasi kepada masyarakat terkait pelestarian wilayah pesisir sebagai upaya meningkatkan kesadaran masyarakat dalam menjaga lingkungan khususnya di daerah pesisir.

\section{Metode}

Kegiatan pengabdian yang dilakukan untuk menyelesaikan masalah tersebut yaitu dengan melakukan pendidikan/edukasi masyarakat yang bertujuan untuk meningkatkan pemahaman serta kesadaran masyarakat tentang pentingnya pelestarian daerah pesisir. Kegiatan dilaksanakan melalui seminar yang ditujukan kepada masyarakat Kota Tanjungpinang yang dilaksanakan pada hari Kamis, 12 Desember 2019 di Gedung Auditorium Universitas Maritim Raja Ali Haji (UMRAH) Dompak. Metode yang dilakukan dalam pengabdian masyarakat terdiri dari 4 tahap yaitu Analisis situasi, Kajian literatur, Persiapan dan Pelaksanaan.

1. Analisis situasi

Analisis situasi bertujuan agar memahami jenis permasalahan yang ingin ditangani dalam program Edukasi Kepada Masyarakat terkait pelestarian daerah pesisir, permasalahannya yaitu: semakin kecilnya wilayah hutan mangrove di daerah pesisir

2. Kajian literatur

Kajian literatur mengenai bagaimana melestarikan ekosistem mangrove

3. Persiapan

Hal-hal yang dipersiapkan meliputi materi yang akan disampaikan dalam edukasi masyarakat.

4. Pelaksanaan

Pelaksanaan didahului dengan edukasi kepada masyarakat tentang pentingnya menjaga kelestarian mangrove, dan arahan tentang bagaimana menanam mangrove, terakhir penutup dengan menyampaikan banyak 
[69] Elfa Oprasmani, dkk / To Maega : Jurnal Pengabdian Masyarakat, Vol.3; No.2; Agustus, 2020

terima kasih kepada pihak-pihak yang telah membantu terlaksananya kegiatan ini.

\section{Hasil dan Pembahasan}

Kegiatan pengabdian berupa pendidikan/edukasi kepada masyarakat Kota Tanjungpinang melalui seminar yang dilaksanakan pada hari Kamis, 12 Desember 2019 di Gedung Auditorium Universitas Maritim Raja Ali Haji (UMRAH) Dompak. Kegiatan bertemakan "Membangun Masyarakat Peduli Lingkungan melalui Edukasi kepada Masyarakat Kota Tanjungpinang terkait Pelestarian Daerah Pesisir". Kegiatan ini juga dihadiri oleh Asisten II Sekretaris Daerah Kota Tanjung Pinang, Bapak Irwan, S.Sos., M.M., perwakilan dari Balai Pengelolaan Daerah Aliran Sungai dan Hutan Lindung (BPDASHL), perwakilan dari Dinas Lingkungan Hidup (DLH) Kota Tanjungpinang masyarakat umum, aktivis lingkungan, guru dan mahasiswa dari berberapa universitas yang ada di Kota Tanjungpinang.

Peserta seminar melakukan registrasi ulang terlebih dahulu sebelum mengikuti seminar pada pukul 07.30-8.00 WIB. Kegiatan seminar diawali dengan pembacaan Al-Quran pada pukul 08.30, selanjutnya tari persembahan oleh mahasiswa Prodi Pendidikan Biologi Fakultas Keguruan dan Ilmu Pendidikan (FKIP UMRAH). Kegiatan ini dibuka langsung oleh Bapak Prof. Dr. Syafsir Akhlus, M.Sc, selaku Rektor UMRAH.

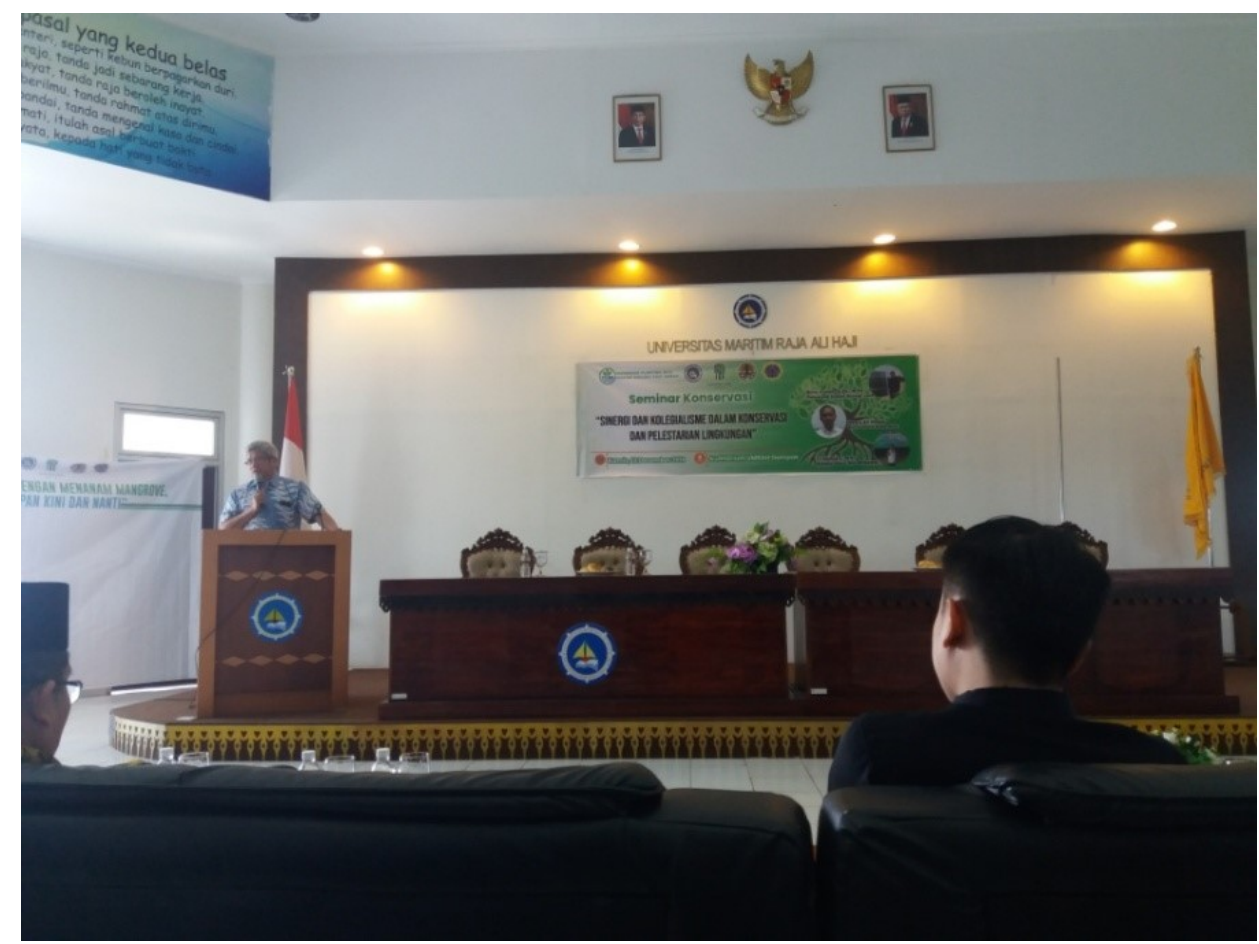

Gambar 1 Pembukaan oleh Rektor UMRAH

Kegiatan edukasi masyarakat ini dilakukan secara paralel oleh 3 orang pemateri yaitu Bapak Henry Al Singer, S.Si (Corporate Social Responsibility (O)To Maega / Jurnal Pengabdian Masyarakat. This is an open access article under the CC BY-SA 4.0 license (https://creativecommons.org/licenses/by-sa/4.0/). 
(CSR) Manager Banyan Tree) Bintan, Bapak Bony Irawan, S.Pd., M.Pd. (Koordinator Kelompok Kajian Biologi Laut), dan Ibu Ir. Surmiati, M.Si (Kepala Seksi Rehabilitasi Hutan dan Lahan, BPDASHL). Seminar dipandu oleh moderator yakni Ibu Elfa Oprasmani, S.Pd., M.Pd., selaku tim pengabdian masyarakat.

Pada seminar dipaparkan mengenai luas serta kelestarian mangrove semakin menurun seiring dengan peningkatan jumlah penduduk serta perkembangan kota dan pembangunan diberbagai sektor. Alih fungsi lahan hutan mangrove semakin bertambah luas baik yang dilakukan oleh pengusaha, perorangan maupun kelompok. Hal ini berdampak negatif bagi kehidupan masyarakat khususnya masyarakat daerah pesisir seperti terjadinya abrasi, biota perairan seperti ikan semakin berkurang, serta terjadi pendangkalan daerah pesisir. Padahal ekosistem mangrove berperan dalam berbagai hal seperti mengendalikan abrasi pantai, mengurangi tiupan angin serta terjangan gelombang laut, mempercapat laju sedimentasi, menyerap serta mengurangi pencemaran, sebagai habitat flora dan fauna, serta berperan dalam sosial ekonomi. Pada pemaparan materi disajikan peta mangrove di Tanjungpinang tahun 2009.

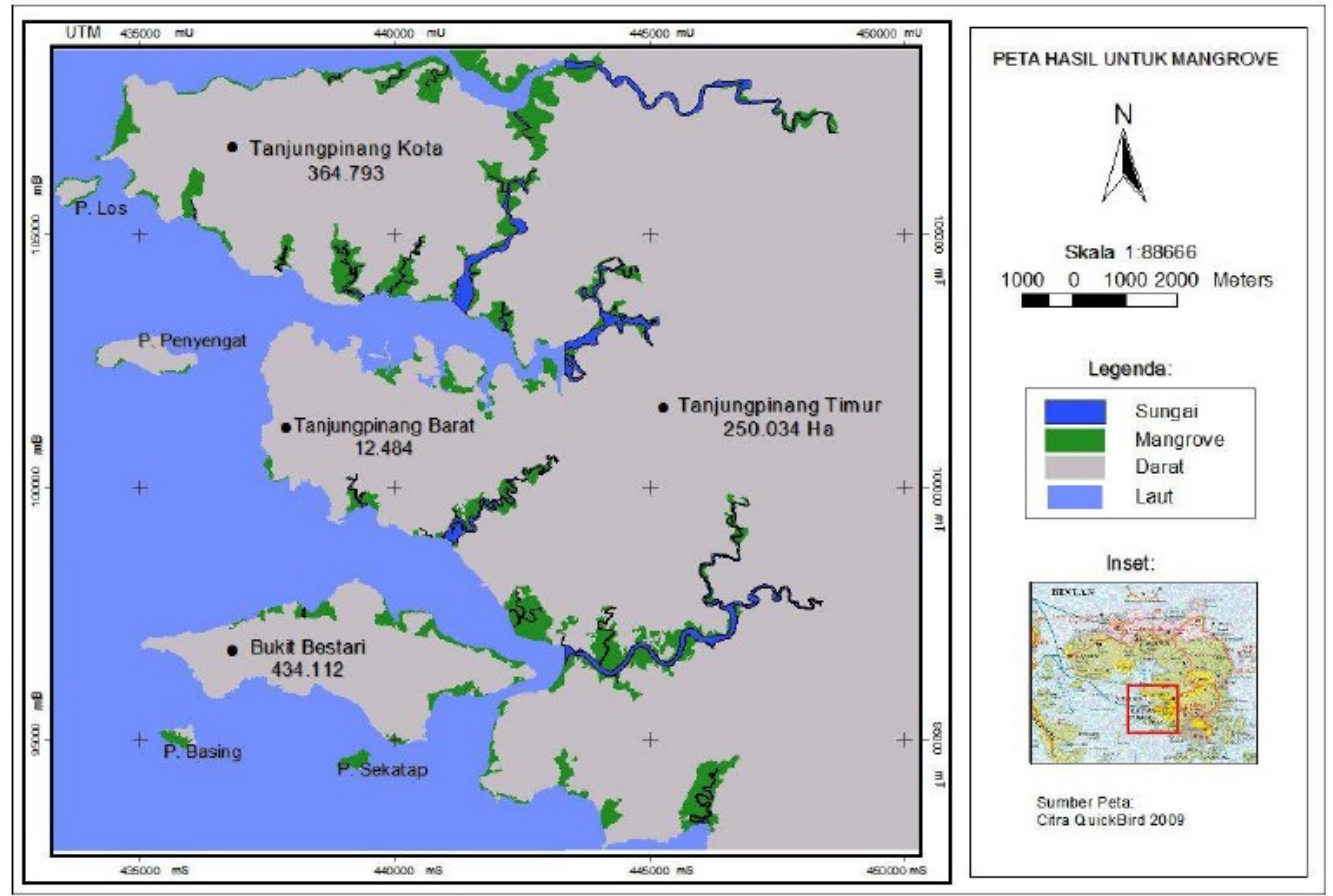

Gambar 2. Peta Mangrove di Tanjungpinang (Sumber Peta: Citra QuickBird 2009)

Peran serta masyarakat bersama-sama dengan pihak terkait sangat diperlukan dalam melestarikan daerah pesisir khususnya ekosistem mangrove dengan cara tidak membuang sampah sembarangan, serta melakukan rehabilitasi ekosistem mangrove. Selain itu peran serta perusahaan yang ada di Pulau Bintan sebagai bentuk respon sosial kepada masyarakat. CSR Banyan Tree sebagai mitra 
pada kegiatan ini juga telah melakukan kegiatan konservasi bersama masyarakat untuk menjaga lingkungan yang ada di sekitar Pulau Bintan.

Pendidikan juga merupakan sarana dalam membentuk karakter, sehingga dengan adanya pendidikan berorientasi lingkungan dapat diharapkan kepedulian dan kesadaran pelestarian lingkungan dapat terinternalisasi dengan baik. Pendidikan merupakan sistem yang masif, terkontrol dan sistematis serta dapat dievaluasi yang dapat menjangkau seluruh masyarakat sehingga mereka menjadi peka terhadap pembentukan karakter salah satunya karakter mencintai lingkungan sekitar. Permasalahan lingkungan masih memprihatinkan karena aktivisme, voluntarisme dan aksi sporadis bukanlah solusi yang tepat, perlu penanaman karakter melalui proses pembelajaran yang berorientasi lingkungan untuk meningkatkan kesadaran masyarakat sejak dini. Kolaborasi dan sinergisme diperlukan antara akademisi, masyarakat, pemerintah, media massa, sekolah dan Corporate. Akademisi berperan dalam mengkonsep, mengkaji dan sebagai inisiator dalam menjaga lingkungan. Masyarakat sebagai subjek sekaligus target usaha konservasi. Pemerintah sebagai otoritas pembuat kebijakan dan ekseutor utama. Sekolah memegang peran vital dalam membentuk karakter bangsa terkait hak, jangkauan dan keluasan sistemnya. Media masa sebagai pembentuk opini publik.

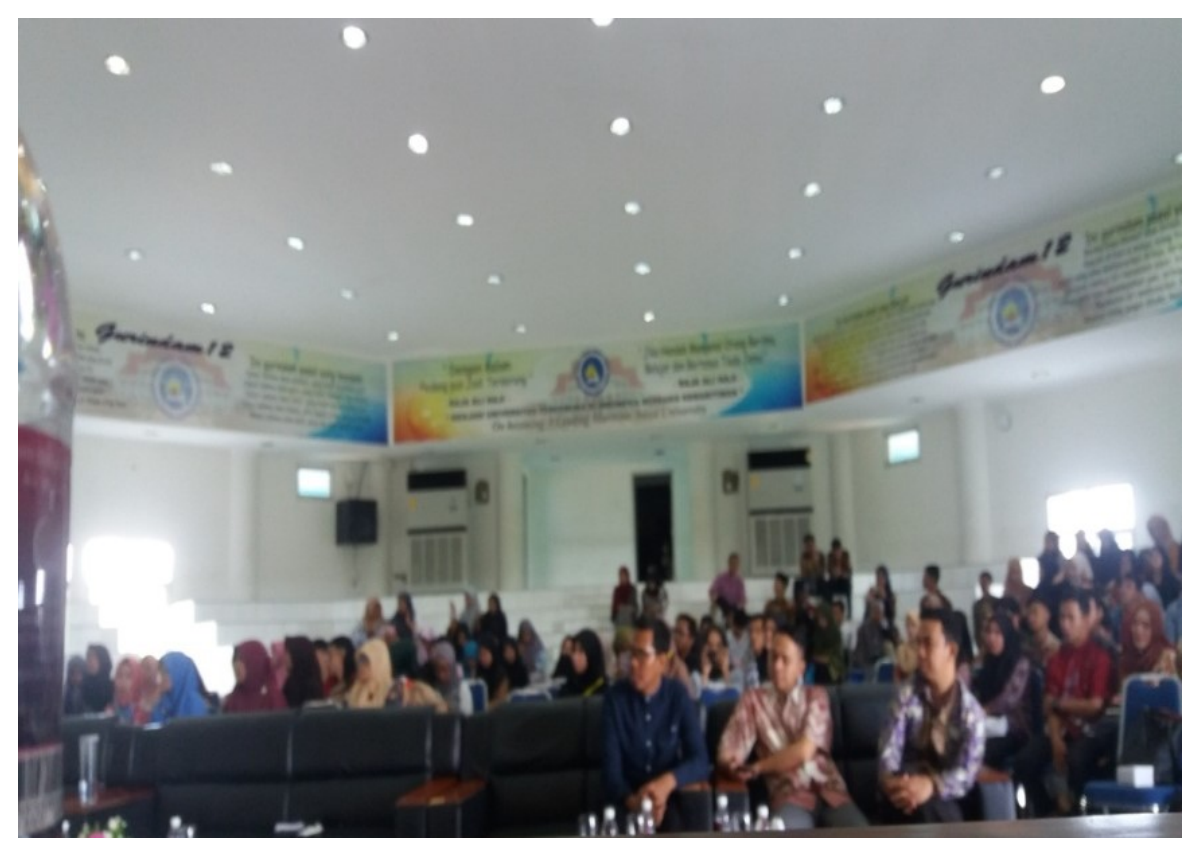

Gambar 3 Pelaksanaan Edukasi Masyarakat Pesisir

Dari pemaparan para pemateri menunjukkan bahwa peran serta setiap komponen masyarakat khususnya masyarakat pesisir sangat diperlukan dalam menjaga kelestarian ekosistem mangrove yang ada di Kota Tanjungpinang. Kesadaran diperlukan masyarakat yang tinggi dalam mempertahankan pelestarian lingkungan hidup (Purba dan Yunita, 2017). 
Setelah materi dipaparkan oleh para pemateri, selanjutnya dibuka sesi tanya jawab yang dipandu oleh moderator. Peserta seminar terlihat sangat antusias mengikuti kegiatan, mulai dari awal hingga akhir kegiatan seminar. Hal ini terlihat dari pertanyaan-pertanyaan yang ditampung dari kegiatan seminar yang berkaitan dengan pelestarian daerah pesisir khususnya ekosistem mangrove. Pertanyaan yang diperoleh dari beberapa peserta seperti aktivis lingkungan hidup, mahasiswa, dan guru. Pada akhir kegiatan dilakukan penanda tanganan janji untuk melestarikan lingkungan. Kegiatan edukasi berjalan dengan baik. Pendidikan kepada masyarakat yang berjalan dengan baik berpotensi untuk membentk kesadaran masyarakat dalam melestarikan lingkungan dapat mencapai hasil yang efektif (Karim, 2017).

Kegiatan edukasi ini perlu dilakukan secara berkelanjutan untuk semua masyarakat yang ada di daerah Kota Tanjungpinang khususnya serta masyarakat Kepulauan Riau pada umumnya demi meningkatkan kesadaran masyarakat. Hal ini dilakukan untuk menghabituasikan masyarakat untuk menjaga daerah pesisir. Masyarakat perlu dibiasakan agar masyarakat telatih untuk mendukung pelestarian lingkungan hidup sehingga diharapkan terjadi perubahan perilaku sacara menetap dan otomatis pada masyarakat (Saputra, 2017). Pada kegiatan ini hanya terbatas edukasi masyarakat, belum terdapat evaluasi kepada masyarakat setelah dilakukan pengabdian dan belum ditunjang dengan aksi pelestarian daerah pesisir seperti konservasi mangrove secara langsung, sebagai bentuk keterlibatan masyarakat dalam menjaga kelestarian daerah pesisir khususnya ekosistem mangrove di Kota Tanjungpinang.

\section{Kesimpulan}

Edukasi kepada masyarakat tentang pentingnya melestarikan ekosistem mangrove di daerah pesisir terlaksana dengan baik. Kegiatan ini perlu dilakukan sebagai upaya meningkatkan kesadaran, kepedulian dan mendorong keterlibatan masyarakat dalam menjaga ekosistem mangrove yang ada di daerah pesisir. Keterlibatan masyarakat dalam melestarikan lingkungan pesisir akan memberikan dampak positif untuk lingkungan. Kegiatan pengabdian ini memaparkan tentang fungsi dan manfaat dari ekosistem mangrove, dampak terhadap kehidupan apabila ekosistem mangrove semakin berkurang serta upaya yang dapat dilakukan oleh masyarakat dalam mencegah berkurangnya ekosistem mangrove serta peran serta dunia pendidikan dan perusahaan dalam menjaga ekosistem mangrove.

Kegiatan edukasi ini perlu dilakukan secara berkelanjutan untuk semua masyarakat yang ada di daerah Kota Tanjungpinang khususnya serta masyarakat Kepulauan Riau pada umumnya. Perlu dilakukan kegiatan penanaman pada daerah ekosistem mangrove yang telah mengalami kerusakan sebagai upaya rehabilitasi kawasan tersebut, serta kegiatan lain yang menunjang pelestarian daerah pesisir. 
[ 73 ] Elfa Oprasmani, dkk / To Maega : Jurnal Pengabdian Masyarakat, Vol.3; No.2; Agustus, 2020

\section{Ucapan Terimakasih}

Ucapan terimakasih ditujukan kepada Universitas Maritim Raja Ali Haji, Program Studi Pendidikan Biologi, Mahasiswa Pendidikan Biologi, CSR Banyan Tree, BPDASHL dan pihak-pihak yang terkait dengan terlaksananya kegiatan pengabdian ini.

\section{Daftar Pustaka}

Barenlitbang Provinsi Kepulauan Riau. (2017). Potensi Kepri. https://barenlitbangkepri.com/potensi-kepri/. (Diakses tanggal 29 November 2019).

Indriawati, P. dan Retnowaty. (2018). Pemberdayaan Masyarakat Dalam Upaya Pelestarian Ekosistem Pesisir dan Hutan Mangrove Manggar. Jurnal Bagimu Negeri, 2(1) 29-38.

Karim, A. (2017). Mengembangkan Kesadaran Melestarikan Lingkungan Hidup berbasis Humanisme Pendidikan Agama. Edukasia: Jurnal Penelitian Pendidikan Islam, 12 (2) 309-330.

Kurniati, E. dan Nazaki. (2107). Implementasi Peraturan Daerah Kota Tanjungpinang No. 2 Tahun 2013 Tentang Izin Penimbunan Lahan (Studi Tentang Pemberian Izin Penimbunan Hutan Mangrove di Kota Tanjungpinang). Kemudi: Jurnal Ilmu Pemerintahan, 2 (1) 115-134.

Lestari, F. (2015). Komposisi Jenis dan Sebaran Ekosistem Mengrove di Kawasan Pesisir Kota Tanjungpinang, Kepulauan Riau. Dinamika Maritim, IV (1) 6875.

Pratiwi, D.A. (2015). Pemberdayaan Masyarakat RW 12 dalam Kegiatan Penghijauan Lingkungan di Kavling Mandiri Kelurahan Sei Pelunggut. Minda Baharu 1(1) 25-32.

Purba, E. S. dan Yunita, S. (2017). Kesadaran Masyarakat dalam Melestarikan Fungsi Lingkungan Hidup. Jurnal Pendidikan Ilmu-Ilmu Sosial, 9 (1) 57-71.

Rahmawati, Firmansyah, A. Syarif, dan Arwati, S. (2020). Penyuluhan dan Pelatihan Olahan Sagu Menjadi Produk Brownies dan Cookies Pada Tim Penggerak Pkk Desa Purwosari Kecamatan Tomoni Timur Kabupaten Luwu Timur. To Maega: Jurnal Pengabdian Masyarakat, 3 (1) 23-30.

Saputra , M. (2017). Pembinaan Kesadaran Lingkungan Melalui Habituasi Berbasis Media Sosial Guna Menumbuhkan Kebajikan Moral Terhadap Pelestarian Lingkungan. Jurnal Moral Kemasyarakatan, 2 (1) 14-29.

Tjandra, E. dan Siagian, Y.R. (2011). Mengenal Hutan Mangrove. Bogor: Cita Insan Madani. 